$\xi=1$ 国

\title{
The Ecological Estimation of Sredniy Kaban Lake Based on Molecular Methods
}

\author{
M. Khusainov, Ludmila L. Frolova \\ Kazan Federal University \\ *Corresponding author E-mail: Shade0602@yandex.ru, \\ Tel. +79274218171
}

\begin{abstract}
Sredniy Kaban lake is part of the system of Kaban urban lakes, experiencing anthropogenic load, and being currently used for sporting events in rowing. Monitoring of the reservoir is carried out regularly with restoration and improvement activities, and green beaches landscaped. Assessment of the ecological state of the reservoir and the surrounding environment is carried out by different methods, one of the main is bioindication. The method is based on the study of indicator species, identified by obsolete methods based on their morphological features. As an alternative to the visual approach with the use of a microscope, the paper considers a method for identifying hydrobionts by the CO1 marker gene based on the DNA-barcoding method and modern sequencing methods. The sequenced sequences of the fragment of the CO1 hydrobiont gene of freshwater Sredniy Kaban lake in the autumn (2016) and summer (2017) sampling periods in the fastq format are included in the international database on the NCBI's website with unique numbers SRR5852708 (2016) and SRR5839796 (2017). The paper presents the results of the analysis and gives an assessment of the water quality of Sredniy Kaban lake (Kazan, Russia). Comparative analysis of metagenomic data shows that most of the animals of Sredniy Kaban lake are grouped near the b-mesosaprobic zone in 2016, and o-saprobic zone in 2017. By water quality Sredniy Kaban lake is transitional from b-o-saprobic to b-amesosaprobic as of the results of 2016, and according to the results of 2017 - from b-o-saprobic to o-saprobic, which is due to the restoration activities carried out during this period on Sredniy Kaban lake.
\end{abstract}

Keywords: bioindication, saprobity, DNA-barcoding, next-generation sequencing..

\section{Introduction}

Sredniy Kaban lake is part of the system of Kaban urban lakes, experiencing anthropogenic load, and being currently used for sporting events in rowing. Monitoring of the reservoir is carried out regularly with restoration and improvement activities, and green beaches landscaped. Assessment of the ecological state of the reservoir and the surrounding environment is carried out by different methods, one of the main is bioindication. The method is based on the study of indicator species, identified by obsolete methods based on their morphological features [1]. On the one hand, bioindication methods have a significant advantage, since the presence of indicator species of organisms makes it possible to more accurately judge the quality of water in a water reservoir [2]. On the other hand, there is the problem of accurate identification of indicator organisms by their morphological features, because many species have very small dimensions, some species have strong sexual dimorphism, or vice versa, there are sibling species and fewer than all specialists can identify the organism at its larval stage [3].

At present, methods of molecular genetic analysis allow for instrumental identification of organisms accurate to species. Thus, for example, the DNA-barcoding method [4] is used for this purpose. Numerous DNA barcodes by kinds of organisms are accumulated in the international database of nucleotide sequences GenBank and in Barcode of life data system (BOLD) database [5]. The DNA-barcoding method is based on a sequence of nucleotides of the DNA-barcode, which is the same inside the species and differs in different species, for example, for animals - it is a variable fragment of the $\mathrm{CO} 1$ gene with a length of $600-700$ base pairs [7]. Previously, we used this technique to identify zooplankton organisms with DNA-barcode CO1 for assessing the environmental state of freshwater reservoirs by bioindication [8]. In addition, to assess the environmental state of freshwater reservoirs on the basis of modern methods of bioinformatics, we have shown the correlation between the product of the $\mathrm{CO} 1$ gene and the saprobity of the indicator species of rotifers [9].

This paper provides an assessment of the water quality of Sredniy Kaban lake (Kazan, Russia) using the CO1 marker gene of the indicator species of hydrobionts based on the next-generation sequencing method.

\section{Methods}

Sampling from Sredniy Kaban lake (Kazan) was conducted in September 2016 and in July 2017 in accordance with standard hydrobiological methods [10] and using the Apstein network by straining 100 liters of water.

Isolation of DNA from the precipitate obtained by centrifugation of $50 \mathrm{ml}$ of the sample at a rate of $10,000 \mathrm{~g}$ for $15 \mathrm{~min}$ was carried out using the FAST DNA Kit (MP biomedicals) according to the manufacturer's protocol. Amplification of the isolated DNA was performed by Phusion High-Fidelity DNA polemerase (Thermo Fisher) using the primers (Table 1). 
Table 1:

\begin{tabular}{|c|c|}
\hline Primers & Sequences \\
\hline $\begin{array}{l}\text { COI_ZplankF1 } \\
\text { _I (forward } \\
\text { primer) }\end{array}$ & $\begin{array}{l}5^{\prime}- \\
\text { tcgtcggcagcgtcagatgtgtataagagacagtctaswaatcataarga- } \\
\text { tattgg-3' }\end{array}$ \\
\hline $\begin{array}{l}\text { COI_ZplankR1 } \\
\text {-I } \\
\text { (reverse primer) }\end{array}$ & $\begin{array}{l}\text { 5'- } \\
\text { gtctcgtgggctcggagatgtgtataagagacagttcaggrtgrccraar- } \\
\text { aatca-3' }\end{array}$ \\
\hline
\end{tabular}

Purification of the PCR products was carried out with Agencourt AMPure XP beads (Beckman Coulter), followed by a second PCR for indexing the samples (Nextera XT indices). The resulting DNA libraries were sequenced on an Illumina MiSeq (MiSeq Reagent kit v3). Metagenomic data were included in the international database on the NCBI's website [5].

The obtained metagenomic data was aligned with the BLAST + program to establish the species diversity and for subsequent analysis.

\section{Results and Discussion}

The sequenced sequences of the fragment of the CO1 hydrobiont gene of freshwater Sredniy Kaban lake in the autumn (2016) and summer (2017) sampling periods in the fastq format are included in the international database on the NCBI's website under numbers SRR5852708 (2016) and SRR5839796 (2017). After filtering the reads by quality, trimming the service sequences, and removing the chimeric sequences, the resulting nucleotide sequences were aligned with the BLAST + program to establish the taxonomic composition. The sequencing of the sequences of the fragment of the CO1 hydrobiont gene of freshwater Sredniy Kaban lake in autumn (2016) and summer (2017) helped us to identify by years respectively: 242/366 species of bacteria, 179/212 species of animals, $42 / 11$ species of protists, $26 / 3$ of plant species and $2 / 2$ species of fungi. The percentage ratio of the taxonomic groups of Lower Kaban lake (autumn 2016 / summer 2017) is shown in Fig. 1.

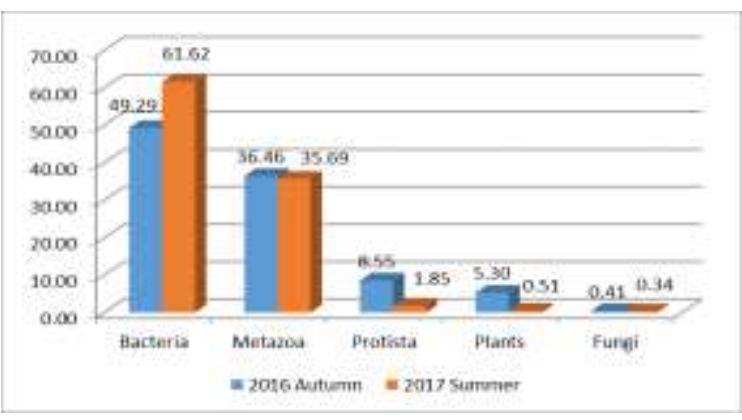

Figure 1:. The percentage of taxons of Sredniy Kaban lake (Autumn 2016; Summer 2017)

The percentage of taxonomic groups of Sredniy Kaban lake by reads (autumn 2016 / summer 2017) is: bacteria - 52.73\%/12.01\%, animals - $41.86 \% / 87.40 \%$, plants - $3.04 \% / 0.02 \%$, protists $2.34 \% / 0.49 \%$ and fungi $0.03 \% / 0.07 \%$ (Figure 2).

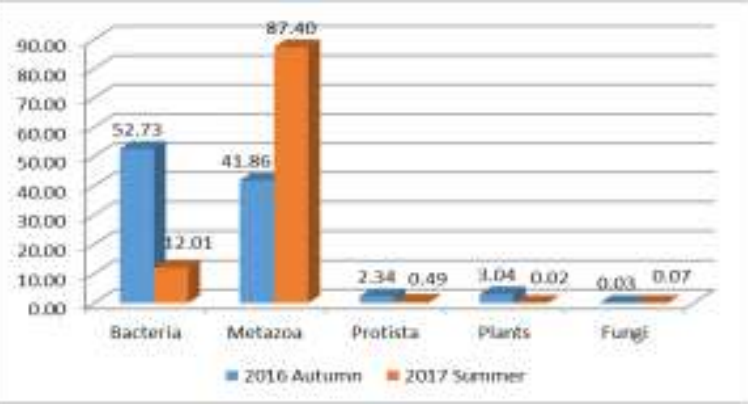

Figure 2:. The percentage of taxons by reads of Sredniy Kaban lake (Autumn 2016; Summer 2017)
The taxonomic groups of Metazoa are analyzed further, since DNA bar-code (CO1) can only be used to identify animal organisms.

In terms of the diversity of species we identified by years 2016/2017: 5/2 species of amphibians, $2 / 1$ species of sponges, 2/4 species of echinoderms, $13 / 5$ species of cnidarians, $2 / 2$ species of columbolus, $22 / 20$ species of rotifers, $3 / 8$ species of mammals, $1 / 0$ species of millipedes, 24/26 species of mollusks, 29/62 species of insects, 25/24 species of arachnids, 2/9 bird species, 13/20 species of crustaceans, $3 / 2$ species of reptiles, 14/11 species of fish and $18 / 15$ species of worms.

The results of the sequenced sequences of the fragment of the CO1 hydrobiont gene of freshwater Sredniy Kaban lake in autumn (2016) and summer (2017) by diversity of species of Metazoa are given in percentage in Table 2 and are shown in Fig. 3.

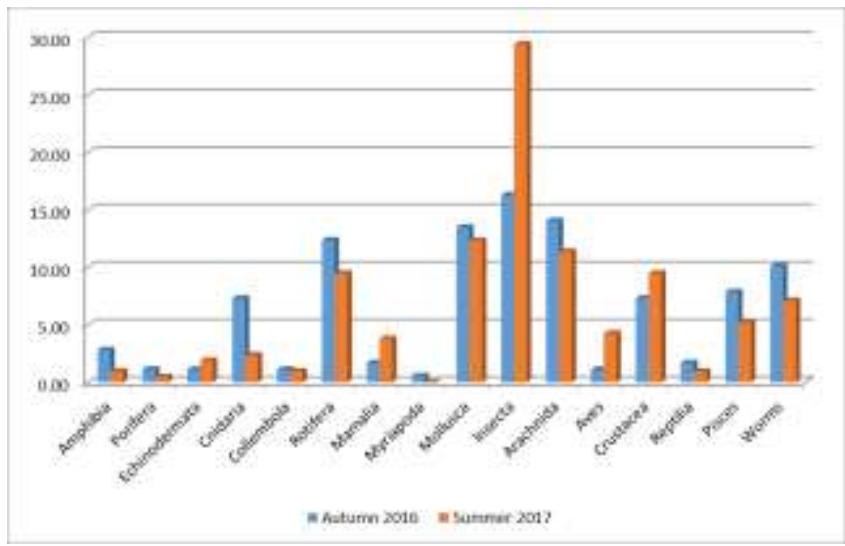

Figure 3:. The percentage of species diversity of Metazoa in of Sredniy Kaban lake

(Autumn 2016; Summer 2017)

In terms of the number of organisms we identified by years 2016/2017: 23/2 reads of amphibians, $2 / 3$ reads of sponges, $3 / 34$ reads of echinoderms, 18/48 reads of cnidarians, $2 / 27$ reads of columbolus, 1028/7106 reads of rotifers, $12 / 40$ reads of mammals, $1 / 0$ reads of millipedes, $812 / 326$ reads of mollusks, $66 / 332$ reads of insects, 88/98 reads of arachnids, 2/36 reads of bird, 226/2143 reads of crustaceans, $3 / 3$ reads of reptiles, $35 / 100$ reads of fish and $658 / 408$ reads of worms.

The results of the sequenced sequences of the fragment of the CO1 hydrobiont gene of freshwater Sredniy Kaban lake in autumn (2016) and summer (2017) by number of organizms of Metazoa are given in percentage in Table 3, and Fig. 4 shows organisms whose quantity exceeds $1 \%$.

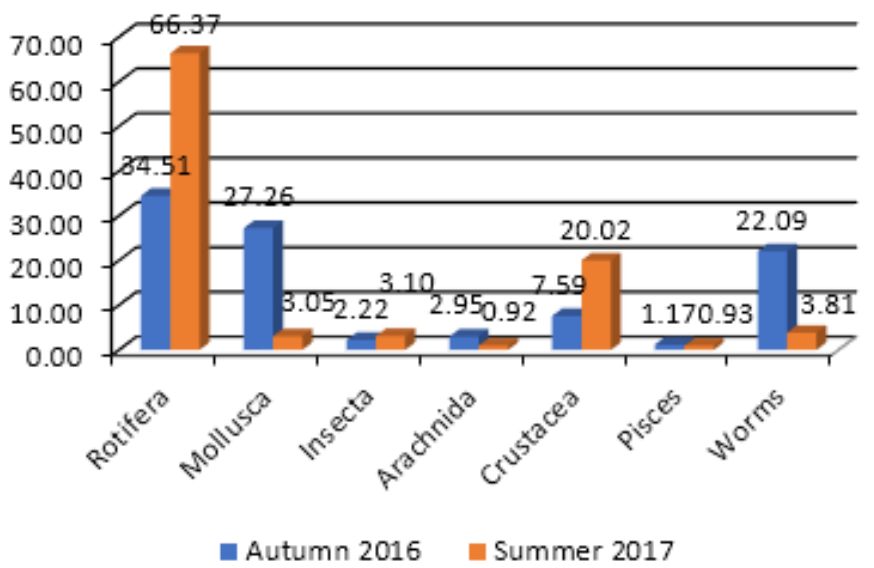

Figure 4:. The quantity of Metazoa organisms (the quantity of reads) in the percentage of Sredniy Kaban lake (Autumn 2016; Summer 2017) 
The analysis of the metagenomic data on the $\mathrm{CO} 1$ gene fragment of the animal organisms of Sredniy Kaban lake (autumn 2016) identified 893 organisms classified as indicators as per V. Sladechek's list of the indicator organisms [11]:

- 888 rotifers:

-40 organisms of Brachionus calyciflorus. referring to b-amesosaprobic zone with an indicator weight of 2.50 ;

-241 organisms of Brachionus plicatilis and 2 reads of species Brachionus quadridentatus - to the b-mesosaprobic zone with an indicator weight of 2,00;

-429 organisms of the same species Keratella cochlearis - to the bo-saprobic zone with an indicator weight of 1.55 ;

-136 organisms of Polyarthra dolichoptera, 38 Polyarthra remata, 1 Trichocerca elongata and 1 organism Conochilus hippocrepis referring to the o-saprobic zone with an indicator weight of 1.00 1.15

- 3 mollusks of the same species Dreissena polymorpha referring to o-b-mesosaprobic zone with an indicator weight of 1.50 ;

- 2 crustaceans of the same species of Mesocyclops leuckarti referring to the o-saprobic zone with an indicator weight of 1.25.

The analysis of the metagenomic data on the CO1 gene of the animal organisms of Sredniy Kaban lake (summer 2017) identified 44 organisms classified as indicators as per V. Sladechek's list of the indicator organisms [11]:

-405 rotifers:

-9 organisms of Brachionus calyciflorus, referring to b-amesosaprobic zone with an indicator weight of 2.50;

-7 organisms of Philodina megalotrocha, 18 organisms of Lecane bulla, 35 Adineta vaga, 1 Asplanchna sieboldi, referring to o-bmesosaprobic zone with an indicator weight of 1.50;

-2 organisms of Brachionus sessilis, referring to the bmesosaprobic zone with an indicator weight of 2.00;

-310 organisms of Keratella cochlearis - to the b-o-saprobic zone with an indicator weight of 1.55 ;

-18 organisms of Macrotrachela papillosa, 1 Macrotrachela quadricornifera and 1 Polyarthra remata, referring to the o-saprobic zone with an indicator weight of 0.90-1.00;

- 2 organisms of Rotaria rotatoria and 2 organisms of Testudinella clypeata - to the a-mesosaprobic zone with an indicator weight of 2.80-3.20;

- 56 molluscs:

-54 organisms of Dreissena polymorpha, referring to o-bmesosaprobic zone with an indicator weight of 1.50;

- 2 organisms of Gammarus balcanicus - to the x-saprobic zone with an indicator weight of 2.0;

- 1712 crustaceans of the same species of Mesocyclops leuckarti referring to the o-mesosaprobic zone with an indicator weight of 1.25 .

The percentage of species of hydrobionts by zones of saprobity is shown in Fig. 5.

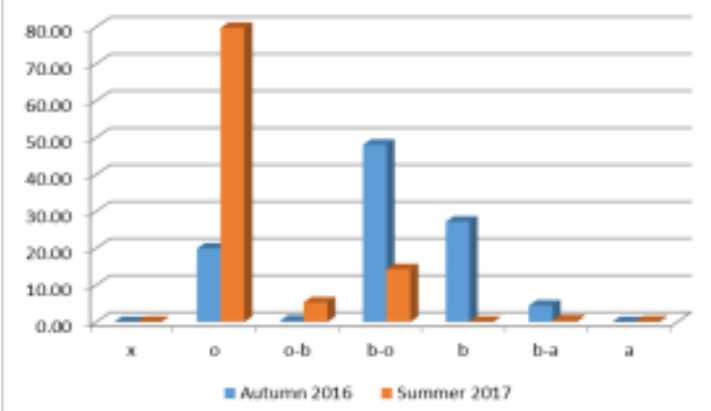

Figure 5:. The percentage of hydrobionts saprobity of Sredniy Kaban lake (Autumn 2016; Summer 2017)
A comparative analysis of metagenomic data shows that most of the animals of Sredniy Kaban lake are grouped around the bmesosaprobic zone in 2016 and o-mesosaprobic zone in 2017 (Fig. 5 ); in summer 2017, animal organisms prevailed (87.40\%) compared with bacterial organisms (12.01\%), whereas in autumn 2016 bacterial organisms $(52.73 \%)$ prevailed insignificantly in Sredniy Kaban lake compared to animal organisms (41.86\%) (Fig. 2), which is due to the flowering of water during this period.

According to the results of the study, Sredniy Kaban lake can be described by water quality as a moderately polluted; its value of the saprobity index is within the b-mesosaprobic contamination zone. By water quality Sredniy Kaban lake is transitional from bo-saprobic to b-a-mesosaprobic as of the results of 2016, and according to the results of 2017 - from b-o-saprobic to o-saprobic, which is due to the restoration activities carried out during this period on Sredniy Kaban lake.

\section{Conclusions}

Assessment of the ecological state of Sredniy Kaban lake using modern methods of next-generation sequencing, molecular and bioinformational analysis was carried out for the first time ever. A new approach in the study shows satisfactory results that can be successfully applied to assess the ecological state of water bodies and the environment. The obtained results are of great practical interest in the field of monitoring of water bodies in particular, and the environment in general.

\section{Acknowledgement}

The work is performed according to the Russian Government Program of Competitive Growth of Kazan Federal University.

\section{References}

[1] V.V. Kurilenko, O.V. Zaitseva, E.A. Novikova, N.G. Osmolovskaia, M.D. Ufimtseva, "Fundamentals of ecology, bioindication and biotesting of aquatic ecosystems", p.448, 2003.

[2] Jana Arturovna KLAAS, Thomas Arturovich KLAAS Econometric Model of Early Diagnosis of a Credit Institution Bankruptcy Risk, Astra Salvensis, Supplement No. 2/2017, p. 107.

[3] Gulnaz Mavletzyanovna GALEEVA, Olga Aleksandrovna AKTASHEVA Forecasting the Dynamics of Foreign Direct Investment in the Russian Economy, Astra Salvensis, Supplement No. 2/2017, p. 137

[4] P.Hebert, S.Ratnasingham, J.R.deWaard, «Barcoding animal life: cytochrome c oxidase subunit 1 divergences among closely related species», Proc Roy Soc Lond B, vol. 270, pp. 96- 99, 2003.

[5] 1 Shatilova L.M., Borisova V.V., Kasatkina O.A. (2018). Representation of the linguistic and cultural concept "lie" in the French and Russian language picture of the world, 34(85), Pp. 194-212.

[6] 2 Bakhyt S., Kalimbetov B., Khabibullayev Z. (2018). Possibilities of Mathematical Problems in Logical Thinking, Development of Secondary Education Pupils, 34(85), P.p. 321-338.L.L.Frolova, A.M.Husainov, «Identification of indicator species of zooplankton organisms by COI gene fragment for estimation of ecological state of a water body», International Journal of Pharmacy \& Technology, vol. 8, № 4, pp. 24477-24486, 2016.

[7] A.M. Khusainov, L.L. Frolova, A.E. Sverdrup, "Identification of correlation between saprobity and the mitochondrial CO1 protein of indicator rotifers on the basis of molecular phylogeny", Bulletin of Technological University, V.21, No.2. pp. 228-233, 2018.

[8] "Methodological recommendations for collecting and processing materials in hydrobiological studies in freshwater. Zooplankton and its products", ZIN AN USSR, p.33, 1982.

[9] V.Sladechek, «System of water quality from the biological point of view», Arch. Hydrobiol. Ergeb. Limnol, pp. 179-191, 1973. 